\title{
Inclusive Financial Development in West Area Based on Catastrophe Theory
}

\author{
Ziyi Zhao ${ }^{1}$ Jinmei Cheng ${ }^{2}$ \\ ${ }^{1}$ Institute of Quantitative \& Technical Economics, Chinese Academy of Social Sciences, \\ Beijing, 100732 \\ ${ }^{2}$ Guizhou University of Finance and Economics, Guiyang, 550025
}

\begin{abstract}
This paper uses the panel data of 12 provinces in Western China for 2008-2015 years and the catastrophe progression method to evaluate the development level of Inclusive Finance. It shows that there is a big difference between inclusive financial development in different provinces and cities in Western china. In terms of financial penetration, availability and use of services, Sichuan, Shaanxi and Chongqing are significantly higher than other provinces and cities, so the degree of financial inclusion is extremely high. The results also show that: on the whole, inclusive financial development trends between the 12 provinces are different, showing different degrees of different phenomenon. The analysis also believes that the catastrophe progression is feasible and reasonable in the evaluation of inclusive financial development in the western region, and it has important reference value for the evaluation of financial inclusive development in other provinces and regions.
\end{abstract}

Keywords

Catastrophe theory; inclusive finance ; finance development ; the west area

\section{基于突变级数法的西部省区普惠金融发 展评价研究}

\author{
赵子铱 ${ }^{1.2}$ 成金妹 ${ }^{2}$ \\ ${ }^{1}$ 中国社会科学院数量经济与技术经济研究所, 北京, 100732 \\ 2 贵州财经大学, 贵州贵阳, 550004
}

摘要: 本文利用 2008-2015 年我国西部 12 省市面板数据, 采用突变级数法评价地区普惠金融 发展水平。结果显示我国西部各省市之间普惠金融发展存在较大差异。在金融渗透性、服务 的可得性和使用情况，四川、陕西、重庆地区要显著高于其他省市，因而金融普惠程度较 高; 发现西部 12 省市间普惠金融发展趋势不同, 呈现不同程度的分化现象。分析还认为, 突变级数在对西部地区进行普惠金融发展评价可行、合理，对其他省市或地区金融普惠发展 评价具有重要的借鉴价值。

关键词:突变级数法; 普惠金融; 金融发展 ; 西部地区 


\section{1.引言}

构建普惠金融体系这一理念首次 提出是在 2005 年联合国 “国际小额信 贷年” 活动上, 至今距离这一理念的 提出也有十二年了。自上世纪 90 年代 以来，普惠金融得到了国际社会的广 泛关注，也成为二十国集团的一个重 要议题。2009 年以来, 国际上先后成 立了普惠金融联盟、二十国集团普惠 金融专家组、全球普惠金融合作伙 伴。在我国, 引入普惠金融概念虽相 对较晚, 但随着经济金融体制改革的 深入，普惠金融受到人们的广泛关 注, 并且在十八届三中全会通过了 《关于全面深化改革若干重大问题的 决议》, 党中央、国务院积极极推进 金融改革与发展, 从国家层面上明确 提出了“发展普惠金融”。

本文在回顾国内外相关文献的基 础上, 运用突变级数法评价西部地区 各省市的普惠金融发展水平。因为西 部地区是我国脱贫攻坚的短板，金融 作为现代经济的核心，基于普惠金融 发展状况可以因地制宜发展金融业, 也可以促进地方经济更快发展, 运用 突变级数法评价普惠金融发展程度必 定还会给中国其他省份普惠金融的发 展起到借鉴作用。本文按照现行中国 统计年鉴中对西部地区的划分标准, 将内蒙古、广西、重庆、四川等 12 个 省市作为研究对象。

\section{2. 文献综述}

对普惠金融发展进行测度和评价 的研究有很多, 内容也比较丰富, 这 部分的研究主要聚焦于如何选取指标 变量和构建普惠金融指数体系。其中 在普惠金融指数构建的指标选择 上,Beck T.（2005）首创性地从银行服 务的可及性和实际使用情况两个维度
选取了八个指标来度量普惠金融发展 水平。 $\operatorname{Sarma}(2008)$ 借鉴联合国人类发 展指数从银行渗透度、银行服务的可 获得性和使用情况三个方面选择人均 ATM 机和人均营业网点、拥有银行账 户的人口比例、存款占 $\operatorname{gdp}$ 比重、贷 款占 gdp 比重等变量, 创建了普惠金 融指数 (IFI)。A Arora(2010)从银行的服 务范围、便利性及成本三个方面选取 人均和单位面积的分支机构数、存贷 款利率、账户管理费、跨行取款费等 指标来分析发达国家和欠发达国家的 金融服务水平的差异。这一研究没有 将金融服务的运用状况纳入考虑的范 围内。在国内, 孙翯和李凌云(2011), 李明贤和李学文(2008), 他们运用层次 分析法和主成分分析法建立农村金融 服务覆盖指标体系，对我国农村金融 覆盖的广度和深度进行评价与分析。 在金融设施使用效率和地理渗透度等 方面的指标，借鉴了 Sarma (2008)的测 算方法来建立评价普惠金融发展程 度。另一些学者对如何构建普惠金融

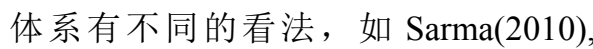
Arora(2010), Gupte(2012) 在构建普惠金 融体系是对各指标采用了同等权重的 主观赋权法，他们忽视了不同指标所 能代表的金融普惠程度不同的事实; 高沛星等(2011)利用变异系数法确定指 标权重, 主要研究营销排斥、价格排 瓜等四个方面, 进而计算出金融排斥 度。李滨（2014）采用因子分析法确 定各指标权重计算普惠金融指数。焦 瑾璞等(2015) 采用层次分析法构建实 证分析模型来区别各指标的重要性与 结构关系的差异。

国内外学者关于评价普惠金融发 展的研究为本文提供了坚实的研究方 法基础, 不足的是, 多数学者虽然在 指标选取上有些差异, 但大都直接采 用 $\operatorname{Sarma}(2008)$ 的普惠金融发展指数测 算方法, 而且, 国内学者对西部地区 普惠金融发展进行针对性的研究并不 
多。突变技术评价法具有不需对评价 指标赋权的优点, 根据各自目标在归 一公式本身中的内在机制决定, 避免 了专家赋权的主观性, 使评价结果具 有合理性。为此, 在参考借鉴国内外 文献的基础上, 采用突变级数法对西 部 12 省市普惠金融发展水平进行评价 研究, 以此探析西部地区金融普惠水 平的发展状况, 为提出有针对性的政 策与建议提供基础。

\section{3.突变级数法评价的基本思想和步骤}

突变级数法建立在突变理论基础 上的数学分析方法, 由法国数学家 Renethom 于 1972 年提出。该方法对评 价目标进行多层次矛盾分解, 然后利 用突变理论与模糊数学相结合产生突 变模糊隶属函数, 再由归一公式进行 综合量化运算, 最后归一为一个参 数, 即求出总的隶属函数, 从而对评 价目标进行排序分析的一种综合评价 方法。并且该方法要求单一状态变量 的控制变量不超过四个, 若为非互补 型突变系统, 取状态变量中控制变量 的最小值为级数, 若为互补性型突变 系统, 则取状态变量中控制变量的平 均值为级数。突变级数法不需要对指 标采用权重, 只考虑各评价指标的相 对重要性, 从而减少了主观性又不失 科学性合理性, 而且计算简易准确。

（1）按突变计数法构建评价指标系统 根据评价对象的特点, 对评价总目 标进行逐层排序的矛盾分解, 组成倒 树状目标系统结构。由普惠金融的发 展评价目标体系逐步分解为控制变量 指标, 将目标层抽象的定性指标分解 得到具体量化的指标, 直至底层可以 直接计量的原始数据指标。评价指标 体系确定后, 采用德尔菲法为同层同 组的指标赋权并按照权重大小排列。

(2) 确定突变系统模型
突变理论中, 突变系统的类型有 控制参数的数目决定, 由于木匾控制 便来那个不超过 4 个, 因而突变系统 类型一共有 7 个。其中常见的突变类 型有 3 个, 分别是尖点突变、燕尾突 变和蝴蝶突变。

(1)尖点突变系统, 其模型是:

$$
f(x)=x^{4}+u x^{2}+v x
$$

(2)燕尾突变系统, 其模型是:

$$
f(x)=\frac{1}{5} x^{5}+\frac{1}{3} u x^{3}+\frac{1}{2} v x^{3}+w x^{2}
$$

(3)蝴蝶突变系统, 其模型是:

$$
f(x)=\frac{1}{6} x^{6}+\frac{1}{4} u x^{4}+\frac{1}{3} v x^{3}+\frac{1}{2} w x^{2}+t x
$$

$f(x)$ 为突变系统中状态变量 $x$ 的势 函数, 其中 $\mathrm{u} 、 \mathrm{v} 、 \mathrm{w} 、 \mathrm{t}$ 为状态变量的系 数。尖点突变系统是指由一个指标分 解为两个子指标组成的系统; 相应的 燕尾和蝴蝶突变系统则分别是一个指 标分解三个、四个子指标组成系统。 因此，普惠金融指标体系的三级指标 中, 前 4 个指标组成蝴蝶突变系统, 中间 两个指标组成尖点突变系统, 后 4 个 指标构成蝴蝶突变系统; 在二级指标 中,基于金融渗透性、服务的可得性及 服务使用情况与普惠金融发展水平构 成燕尾突变系统。

(3) 由突变系统的分歧方程导出归一 公式

归一化公式首先就是要到导出势 函数, 再由势函数的一阶导数和二阶 倒数为零的点得到突变系统的分歧点 集的方程, 最后通过分歧点集方程导 出归一公式, 由归一公式将系统内诸控 制变量的取值范围转化为 0-1 之间。

(1) 点突变系统归一化公式为:

$x_{u}=\sqrt{u}, x_{v}=\sqrt[3]{v}$

(2)燕尾突变系统归一化公式为:

$x_{u}=\sqrt{u}, x_{v}=\sqrt[3]{v}, x_{w}=\sqrt[4]{w}$

(3)蝴蝶突变系统归一化公式为: 
$x_{u}=\sqrt{u}, x_{v}=\sqrt[3]{v}, x_{w}=\sqrt[4]{w}, x_{t}=\sqrt[5]{t}$

(4) 利用归一公式进行综合评价

按照突变数法的要求将控制变量 的值控制在 $[0,1]$ 之间, 这样才能分出 各被评价单位在该指标上的等级,故利 用 $Y i j=(P i j-m i n P i j) /(\max P i j-m i n P i j)$ 函 数式对原始数据进行标准化处理。其 中 $i=1,2 \ldots 1$ 为指标个数, $j=1,2 \ldots 12$ 为研 究对象个数, maxPij,minPij 其中某一 指标下的最大值和最小值。利用归一 公式由下向上逐步计算各被评价单位 的评价指标所控制变量的突变级数, 根 据 “大中取小” 的原则, 但对互补性 指标用其平均数代替, 选取各评价子 系统的突变级数, 并作为上一层评价 系统各指标的控制变量, 直到得出最 高层总指标的评价结果。

\section{4.我国西部地区普惠金融发展水平实证 研究}

\section{（1）构建评价指标体系}

为科学测度我国西部地区普惠金 融发展水平, 普惠金融发展指数的变 量选取工作至关重要。选取合适的变 量能减少统计工作量, 排除其他无关 变量的干扰, 从而准确评价西部地区 普惠金融发展状况。本文从金融服务 的范围、使用情况这两个维度上, 沿 用杜强、潘怡 ${ }^{1}$ 在的普惠金融的指标体 系中的变量: 有每万人拥有的银行业 金融机构数、每万人拥有的银行业金 融从业人员数和保险密度、保险深 度、各项存款占 GDP 比重、各项贷款 占 GDP 比重。增加存款余额、贷款余 额、人均存款以及人均贷款等四个变 量, 从金融渗透性这一维度上衡量普 惠金融的发展程度。通过以上 10 个变

[1] ${ }^{1}$ 杜强, 潘怡. 普惠金融对我国地区经济 发展的影响研究-一基于省际面板数据的实 证分析 $[J]$, 经济问题探索. 2016(03).
量构建了我国西部地区普惠金融发展 水平的评价指标体系, 如表 1 所示。

\begin{tabular}{|c|c|c|c|}
\hline 一级 & 二级 & 三级 & 对指标的影响 \\
\hline \multirow{10}{*}{$\begin{array}{c}\text { 普惠金 } \\
\text { 融发展 } \\
\text { 水平 }\end{array}$} & \multirow{4}{*}{$\begin{array}{c}\text { 金融渗透度 } \\
\text { A1 }\end{array}$} & 存款余额（亿元）A11 & 正向 \\
\hline & & 贷款余额 (亿元) A12 & 正向 \\
\hline & & 人均存款 万/人) A 13 & 正向 \\
\hline & & 人均贷款（万/人） $\mathrm{A} 14$ & 正向 \\
\hline & \multirow{2}{*}{$\begin{array}{c}\text { 服务可得性 } \\
\text { A2 }\end{array}$} & 每万人拥有的金融网点数 (个) $\mathrm{A} 21$ & 正向 \\
\hline & & $\begin{array}{l}\text { 每万人拥有的金融服务人数（人） } \\
\text { A22 }\end{array}$ & 正向 \\
\hline & \multirow{4}{*}{ 使用情况 A3 } & 保险密度（元/人） A31 & 正向 \\
\hline & & 保险罙度 ( $\mathrm{X}$ ) A32 & 正向 \\
\hline & & 各项存款占 GDP 比重 (X) A33 & 正向 \\
\hline & & 各项贷款占 GDP 比重 (X) A34 & 正向 \\
\hline
\end{tabular}

（2）确定评价体系各层组突变系统类 型

结合突变理论和评价指标系统, 确定各个层组的突变系统模型（见表 1)。一级指标系统控制变量排序为: 金融渗透性、服务的可得性、服务的 使用情况, 控制变量标记为 A1、A2、 A3, 与普惠金融发展水平构成燕尾突 变系统, 为互补型。二级指标系统控 制变量排序为: 金融渗透性与 A11、 A12、A13、A14 构成蝴蝶突变系统, 为互补型; 服务的可得性与 A21、A22 构成尖点突变系统, 为互补型; 服务 的使用情况与 A31、A32、A33、A34 构成蝴蝶突变系统, 为互补型。

(3) 样本选取与数据处理

根据研究的具体情况, 本文按照 现行统计年鉴对西部地区的划分标 准, 将内蒙古、广西、重庆、四川、 贵州、云南、西藏、陕西、甘肃、青 海、宁夏及新疆维等 12 个省市作为主 要研究对象, 并选取 2008-2015 年统计 数据进行分析。对样本中 12 个省市 2008-2015 年的原始数据进行标准化处 理, 将控制变量取值范围控制在 0-1 之 间, 然后按突变级数法的基本原理和 步骤对我国西部地区普惠金融发展水 平进行分析, 普惠金融水平评价结果 及相应排名如表 2 所示。本文数据均 
来自中国统计年鉴、各省市金融运行 报告和统计公报。

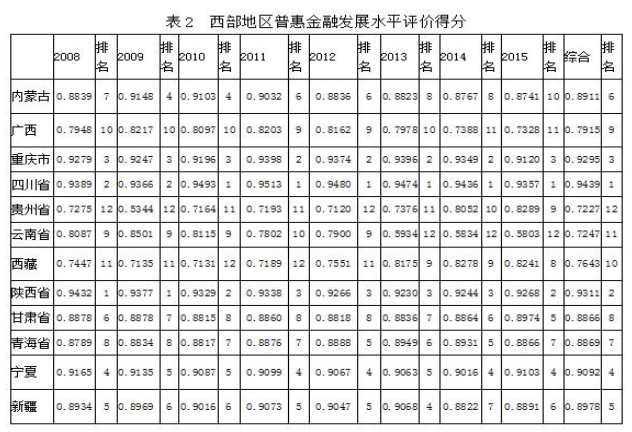

从表 2 反映的结果来看, 在西部 地区各省市普惠金融发展整体状况 中, 四川在 2008-2015 年度里多次位列 第 1 , 其普惠金融发展评价的综合得分 为 0.9439 , 在 2008-2015 年普惠金融发 展综合评价中排名第 1 , 其次为陕西、 重庆，综合得分分别为 0.9311 、 0.9295。在综合评价中排列于倒数第 1 位的地区是贵州, 次位是云南, 综合 得分各为 $0.7227 、 0.7247$ 。分析结果显 示，四川、陕西、重庆、宁夏等地区 的经济实力和广大的金融服务覆盖使 其普惠金融水平远高于其他地区，因 而其普惠金融程度较高; 新疆、内蒙 古、青海、甘肃等地区的经济总量及 金融渗透度相对并不高，但其人口数 量相对较少且受到各方支持力度较 大，因而其普惠金融水平为中等; 而 普惠金融程度较低的地区有广西、西 藏、云南、贵州几省。总体来看, 西 部 12 省市普惠金融发展存在较大的差 异性, 普惠金融发展呈现一种非均衡 的发展态势。如图 1 所示。

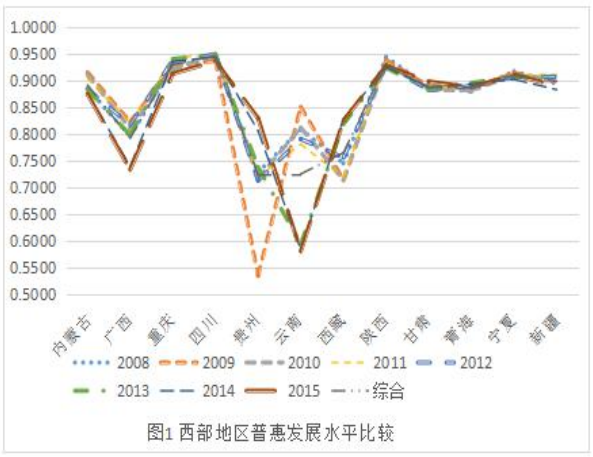

从波动特征来看, 西部 12 省市在 2008-2015 年间的普惠金融发展情形可 分为两类。一类是普惠金融发展水平 极高与较高地区, 这类地区金融普惠 发展平稳, 发展状况表现为整体偏 好。另一类是普惠金融发展水平较低 地区, 这几个省份整体发展趋势波动 明显，尤其是在 2008-2009 年期间，以 及 2013-2015 年间。在 2008-2009 年这 一期间, 主要受到美国次贷危机带来 的负面影响, 2013-2015 年期间欧债危 机以及通货膨胀和房价居高不下等外 部复杂经济金融形势加大了外部金融 风险。具体表现在金融渗透性和服务 可得性上, 存贷余额、人均存贷余额 以及可获得金融服务的覆盖面有较大 的波动。见图 2 所示。

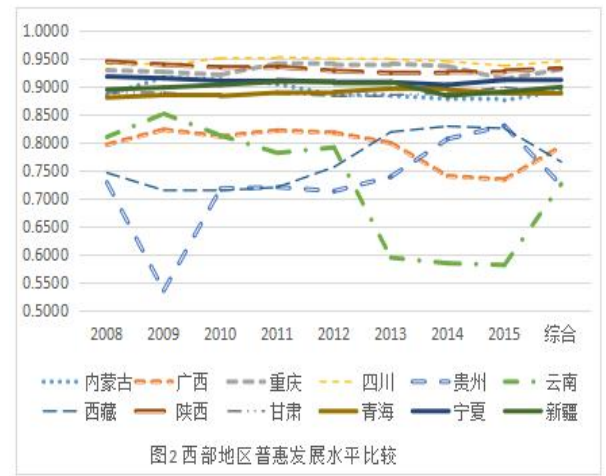




\section{5.结语}

利用突变级数法对西部地区普惠 金融发展水平评价结果，本文认为四 川、陕西、重庆、宁夏为西部 12 省市 中金融普惠程度较高地区, 新疆、内 蒙古、甘肃、青海为金融普惠中等程 度地区, 广西、西藏、云南、贵州是 普惠金融发展水平较低地区, 并得出 以下结论:

（1）在金融渗透性、服务的可得 性和使用情况, 西部 12 省市之间存在 较大差距, 但四川、陕西等地区地区 明显高于其他省份地区, 但云南、贵 州等地区作为后发地区, 经济实力、 城镇化程度等不如其它地区有关, 基 础设施建设相对落后, 居民富裕程度 低于其他地区, 造成获得性和使用情 况也相对落后。

(2) 将西部 12 省市进行综合分 析, 认为西部地区的普惠金融发展同 样存在不均衡现象, 经济较为发达的 重庆、陕西、四川等省市, 普惠金融 程度比较好, 相对发展落后的云南、 贵州等省市普惠金融发展也相对落 后, 其特有的经济实力和地理环境差 别造成不同程度人口聚集等原因, 使 得获得性和使用情况发生较大差别; 西部地区的省市基础设施建设极为不 均衡, 贵州省尤为突出; 各省市之间 的发展趋势不同, 出现不同程度的分 化。

总之, 本文基于突变级数法对我 国西部省区普惠金融发展水平的评价 较好吻合了西部 12 省市经济发展状 况, 能够客观、准确地评价其普惠金 融发展水平, 还能为西部地区提出有 针对性的政策与建议提供基础, 给中 国其他省份普惠金融的发展起到借鉴 作用。

\section{致谢}

本文是国家商务部联合基金《基 于大数据的普惠金融创新机制研究》

（课题编号：2016SWB2D14）和贵州 省教育厅重点项目《贵州工业化进程 中的企业融资策略研究》的阶段性研 究成果。

\section{参考文献}

[1] 龙云飞,李晶. 普惠金融发展与地区 经济增长相关性研究——基于 31 省市 2015 年截面数据视角 [J]. 西 南金融,2017,(10).

[2] 杜强,潘怡.普惠金融对我国地区经 济发展的影响研究--基于省际面板 数据的实证分析 $[\mathrm{J}]$, 经济问题探 索. 2016(03).

[3] 蔡洋萍. 中国农村普惠金融发展的 差异分析一一以中部六省为例 $[\mathrm{J}]$. 财经理论与实践,2015,36(06).

[4] 吴应宇,朱兆珍. 基于突变级数法的 创业板上市公司成长态势研究 $[\mathrm{J}]$. 东南大学学报 (哲学社会科学 版),2015,17(01):49-57.

[5] 王婧,胡国晖. 中国普惠金融的发展 评价及影响因素分析 [J]. 金融论 坛,2013,18(06).

[6] 张凌, 周荣, 喻登科. 突变级数法在企 业核心竞争力评价中的应用 [J]. 科 技管理研究,2009,29(10). 